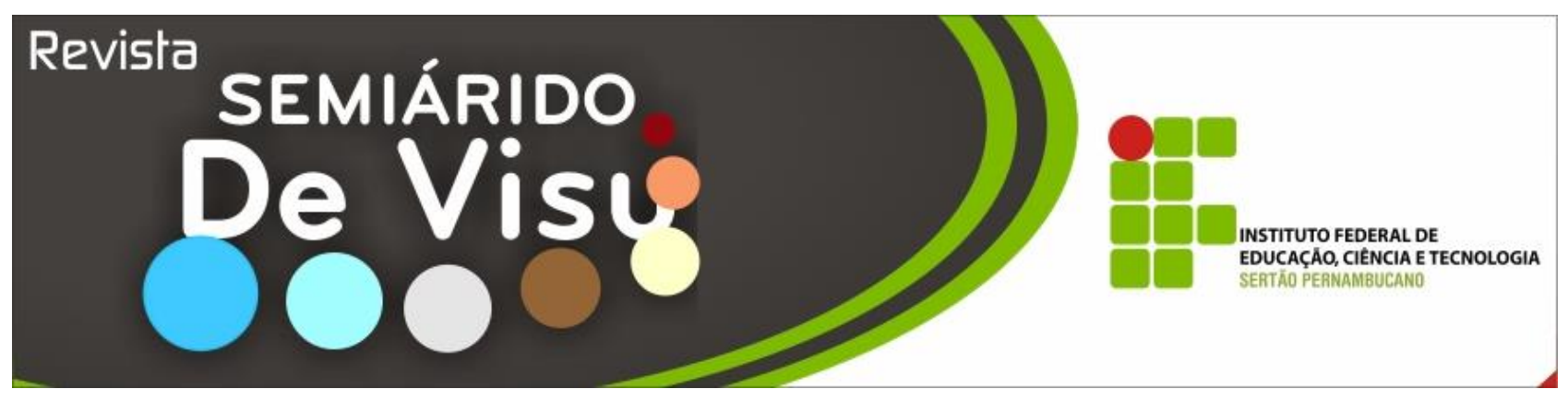

\title{
Energia eólica: desenvolvimento energético e os conflitos socioambientais inerentes à modalidade energética
}

\author{
Francisco das Chagas de Sousa ${ }^{1}$ \\ ${ }^{1}$ Instituto Federal de Educação, Ciência e Tecnologia do Sertão Pernambucano, campus Salgueiro. Cidade de Salgueiro \\ - PE, Km 508, Zona Rural. francisco.chagas@ifsertao-pe.edu.br. Graduado em Química Industrial, Mestre em Química, \\ com área de concentração em Química Orgânica.
}

\begin{abstract}
RESUMO: Um dos assuntos mais recorrentes em todo o mundo atualmente é a preocupação com a demanda energética mundial, concomitante com a utilização de fontes energéticas renováveis. A base da matriz energética mundial é o petróleo, que é um combustível não renovável e com previsibilidade de esgotamento. Além disso, a queima desse combustível, e também de seus derivados, emite Gases de Efeito de Estufa (GEE), responsáveis por boa parte do desequilíbrio ambiental em dias atuais. Dentre as várias formas de produção de energias renováveis, destaca-se a energia eólica. A energia eólica é a energia proveniente dos ventos. Ela é gerada quando as massas de ar movimentam as hélices das torres eólicas, que por sua vez, acionam geradores elétricos. Essa modalidade energética é apresentada como um ótimo recurso, uma vez que geram eletricidade sem agredir ao meio ambiente. Entretanto, tem se discutido muito a funcionalidade ecológica dos parques eólicos, bem como os impactos socioambientais e socioeconômicos provocados nas comunidades próximas a instalação dos parques eólicos. Este trabalho objetiva abordar os contrastes existentes entre o desenvolvimento ambiental e econômico preconizado por governos e grupos empresariais a respeito da energia eólica, e os aspectos socioeconômicos e socioambientais advindos da instalação das usinas eólicas em comunidades. A presente pesquisa emprega metodologia qualitativa, e se configura como uma pesquisa exploratória e descritiva.
\end{abstract}

Palavras-chave: Demanda energética; matriz energética; impactos socioambientais.

\section{Wind energy: energy development and the socio-environmental conflicts inherent to the energy modality}

\begin{abstract}
One of the most recurring issues in the world today is concern about global energy demand, concomitant with the use of renewable energy sources. The basis of the world energy matrix is petroleum, which is a non-renewable fuel with predictability of exhaustion. In addition, the burning of this fuel, and also of its derivatives, emits Greenhouse Gases (GHG), responsible for much of the environmental imbalance in current days. Among the various forms of renewable energy production, wind energy stands out. Wind energy is the energy from the winds. It is generated when the masses of air move the propellers of the wind towers, which in turn, trigger electric generators. This energy modality is presented as a great resource, since it generates electricity without attacking the environment. However, there has been much discussion about the ecological functionality of wind farms, as well as the socio-environmental and socio-economic impacts of communities near the installation of wind farms. This work aims to address the existing contrasts between environmental and economic development advocated by governments and business groups regarding wind energy, and the socioeconomic and socioenvironmental aspects of the installation of wind farms in communities. The present research uses qualitative methodology, and it is configured as an exploratory and descriptive research.
\end{abstract}

Keywords: Energy demand; energy matrix; social and environmental impact 


\section{Introdução}

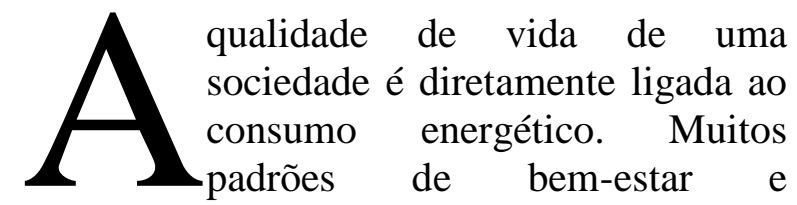
desenvolvimento de uma família são determinados pelo quantitativo energético consumido em um mês. Por esse motivo as questões relacionadas ao abastecimento energético é uma das temáticas de maior importância atualmente, principalmente àquelas relacionadas à segurança do suprimento de energia em médio e longo prazo (MARTINS et. al., 2008) e a uma maior segurança ambiental. Essa preocupação se dá pelo fato da maior parte de toda a energia consumida no mundo ser composta de fontes não renováveis de energia, como gás natural, carvão mineral e principalmente petróleo.

Como se trata de fontes não renováveis, o futuro dessas modalidades energéticas é incerto. Além disso, são altamente poluentes. A queima desses combustíveis emite, além de muitos gases tóxicos, o dióxido de carbono $\left(\mathrm{CO}_{2}\right)$, principal responsável pelo efeito estufa, e consequente aumento da temperatura da superfície terrestre (MOREIRA et. al., 2013). Dessa forma, nas últimas décadas tem sido intensificada a busca por fontes energéticas alternativas e sustentáveis.

Juntamente com a energia solar, a energia eólica é considerada uma das fontes mais promissoras para geração de eletricidade, sendo capaz de permitir a diversificação e a limpeza da matriz elétrica de uma região. Além disso, diminui a dependência de fontes fósseis, e sua matériaprima é amplamente disponível, e independe de exportações (PORTO et. al., 2013).

A energia eólica tem crescido fortemente nos últimos anos. Segundo muitos autores, a utilização dessa modalidade energética traz imensas vantagens do ponto de vista ambiental e econômico. Rodrigues (2017) enumera as principais vantagens desta modalidade energética como sendo: i. $\quad$ Fonte inesgotável;

ii. Não emissoras de gases poluentes;

iii. Não geram resíduos;

iv. Diminui a dependência de combustíveis fósseis;

v. Reduz gastos na importação de petróleo.

A transformação da energia cinética dos ventos já vem sendo utilizada há muito tempo. As primeiras aplicações envolvendo a transformação da força eólica em proveito de atividades do homem foram os moinhos, usados para a transposição de água para níveis elevados, e também a moagem de milho (MARTINS et. al., 2008).

Quando se fala na geração elétrica por meio dos ventos, muitos argumentos em prol do desenvolvimento sustentável e dos benefícios ao meio ambiente são citados. Entretanto os impactos socioeconômicos e socioambientais por quais passam os moradores de regiões próximos a usinas eólicas, poucos são referenciados. O presente trabalho objetiva abordar os contrastes existentes entre o desenvolvimento ambiental e econômico preconizado por governos e grupos empresariais, e os aspectos socioeconômicos e socioambientais advindos da instalação das usinas eólicas em comunidades. De uma forma geral busca demonstrar, sob a luz de aspectos sociais, econômicos e ambientais, as condições favoráveis e desfavoráveis decorrentes da instalação de parques eólicos no Brasil.

\section{Procedimentos metodológicos}

Para a construção do presente trabalho foi realizada uma pesquisa com abordagem qualitativa e também descritiva. Minayo (1994) considera a pesquisa qualitativa como o estudo de fenômenos que não são reduzidos apenas às operacionalizações de variáveis. Ainda segundo o autor a pesquisa qualitativa está inserida em um nível de realidade que não pode ser quantificado, já que trabalha com significados, motivos, consequências, 
causas, aspirações e atitudes que correspondem a um espaço mais profundo de relações.

De acordo com Gil (2002) pesquisas exploratórias proporcionam maior familiaridade com uma problemática, descrevendo as características de determinada população ou um fenômeno. $\mathrm{O}$ embasamento das discussões feitas no presente trabalho foi feita por meio da pesquisa bibliográfica feita em artigos de periódicos, portais especializados, e reportagens de jornais de veiculação diária.

A estratégia para a construção do trabalho seguiu as seguintes etapas: Identificação do problema central; Disposição da problemática bem como suas variantes; abordagens e discussões a partir do levantamento de dados. Todo o trabalho foi estruturado em cima de pesquisa bibliográfica que abordasse o tema, como artigos científicos, artigos técnicos, artigos de jornais, portais eletrônicos, e outros meios de divulgação, para que se tivesse uma boa compreensão das principais hipóteses e fundamentos pertinentes ao tema.

Dessa forma o caráter do presente trabalho é essencialmente exploratório e descritivo. A partir das fontes pesquisadas foi possível apresentar uma discussão mais ampla do assunto, permitindo que o trabalho seja uma fonte de pesquisas e trabalhos futuros.

\section{Referencial teórico}

\section{Cenário energético atual}

Ao longo da história da humanidade, o homem sempre buscou no meio em que habitava condições para o seu desenvolvimento. Dessa forma foi transformando os espaços de acordo com suas necessidades. Inicialmente essa relação se deu de forma harmoniosa. O homem colhia do meio em que vivia apenas o necessário para a sua subsistência, entretanto com o aumento da complexidade pela qual passou a sociedade, essa relação passou a ser desarmoniosa e a relação homem-meio ambiente passou a ter caráter predatório (LEITE \& SOUZA, 2015).

A energia sempre foi um bem essencial à manutenção da atividade humana na terra. Desde um complexo sistema de informações computacionais, até a um simples piscar de olhos, faz-se necessário um dispêndio energético. Nos primórdios da civilização o acesso a energia era praticamente ilimitado, e não oferecia prejuízos notórios ao meio ambiente. Toda a energia de que se necessitava provinha da queima de lenha, tanto para o aquecimento, quanto para o cozimento de provimentos (GOLDEMBERG \& LUCON, 2007).

Aos poucos, com o crescimento populacional e a formação das primeiras grandes cidades, o consumo energético passou a crescer de forma exponencial. A partir desse momento houve a necessidade do incremento de outras fontes energéticas. A Revolução Industrial trouxe consigo uma nova forma de exploração energética. A partir desse ponto da história, passa-se a utilizar o carvão mineral como fonte de energia para a movimentação dos empreendimentos, principalmente na Inglaterra (MOREIRA et. al., 2013).

\section{Combustíveis fósseis e o efeito estufa}

$\mathrm{O}$ rápido desenvolvimento industrial verificado durante o século XVIII impulsionou sobremaneira o uso indiscriminado de fontes não renováveis, e poluentes de energia. $\mathrm{O}$ carvão foi a primeira fonte não renovável a ser utilizada nessa época. Posteriormente com praticidade oferecida pelo uso do petróleo, esse passou a ser adotado pelas indústrias emergentes. $\mathrm{O}$ gás natural passou a ser utilizada mais recentemente, depois do controle de sua exploração e uso de forma a não oferecer riscos tão acentuados. 
A queima de combustíveis fósseis libera uma grande quantidade de energia, resultado de alto poder calorífico que apresentam. Essa energia é utilizada diretamente na realização de processos, ou é transformada e aproveitada posteriormente como energia mecânica ou elétrica. Os principais gases formados a partir da queima dos combustíveis fósseis são: dióxido de carbono $\left(\mathrm{CO}_{2}\right)$, monóxido de carbono $(\mathrm{CO})$, óxido de enxofre $\left(\mathrm{SO}_{2}\right)$, e hidrocarbonetos (HC). Entretanto deve-se ressaltar que não é exclusividade da queima de combustíveis fósseis a emissão de gases de efeito estufa, outras atividades antrópicas são igualmente emissoras, como o agronegócio, e o as queimadas (MOREIRA et. al., 2013).

Entre estes gases o $\mathrm{CO}_{2}$ é o que mais se destaca no momento atual. Ele é o principal subproduto da queima dos combustíveis fósseis, e o principal causador do efeito estufa. $\mathrm{O}$ efeito estufa é um fenômeno que ocorre pelo acúmulo de gases na atmosfera, que impede a dissipação de toda a energia irradiada pela terra. Entretanto, um acúmulo maior de gases na atmosfera impede que haja dissipação adequada do calor, que se é refletido novamente para a superfície da terra, aumento os níveis de temperatura (MENDES et. al., 2016).

Um problema imediato das altas temperaturas é o derretimento das calotas polares, que aumenta o nível do mar, e compromete cidades costeiras ao longo dos litorais. A desertificação de áreas cultiváveis também é uma consequência do aumento de temperatura, bem como as mudanças climáticas.

\section{Sustentabilidade}

Desenvolvimento sustentável baseiase no suprimento de necessidades presentes, sem que haja o comprometimento para gerações futuras. Como afirmam Simas \& Pacca (2013), a busca pelo desenvolvimento sustentável é uma das principais motivações observadas hoje em apoio às energias renováveis.

A sustentabilidade é um ponto primordial para que haja permanência e desenvolvimento do mercado. Entretanto, há dificuldades em se identificar reais ganhos com a adoção dessas práticas. Como não se trata de mecanismos de rápida resposta, o mundo empresarial apresenta dificuldades em enxergar as vantagens. Dessa forma, cabe ao poder público, atuar como um "fiel da balança", incentivando e induzindo boas práticas sustentáveis, bem como cobrando e punindo práticas que não levem a um desenvolvimento socioeconômico adequado aos novos parâmetros mundiais (MARTINS et. al., 2015).

Frente à demanda por recursos energéticos, o Governo Federal estruturou um modelo institucional voltado para a diversificação da matriz elétrica brasileira, focando principalmente as fontes renováveis de energia.

Abreu et. al. (2014) observam que muitos Governos nacionais foram estabelecendo metas para o desenvolvimento de fontes energéticas renováveis. Metas mediadas por políticas de créditos, isenções fiscais, e políticas de financiamentos. No Brasil o PROINFA (Programa de Incentivo às Fontes Alternativas de Energia Elétrica) foi criado para financiar, por meio do Banco Nacional de Desenvolvimento Social (BNDES), projetos de energia eólica, pequenas centrais hidrelétricas e o uso da biomassa (ABREU et. al., 2014).

\section{Energia eólica}

Denomina-se energia eólica a energia contida nas massas de ar em movimento (vento). $\mathrm{O}$ aproveitamento energético vai ocorrer por meio da conversão da energia cinética de translação dos ventos, em energia cinética de rotação das hélices, esta rotação por sua vez, aciona geradores elétricos. Esse conjunto é denominado aerogerador 
(JACINTO, 2016). Como o fator responsável pela movimentação das hélices são as massas de ar, a produção de eletricidade vai ser função da densidade do ar, e da velocidade dessas massas (MARTINS et. al., 2008).

Como a energia eólica compreende a energia cinética contida nos movimentos das massas de ar, a potência gerada pode ser calculada pelo esquema de equações que se seguem:

$$
\mathrm{W}=\mathrm{EC}=\frac{m \cdot v^{2}}{2}
$$

Equação 1. Equação da energia cinética

Associando a Equação 1, com a Equação 2:

$$
\mathrm{P}=\frac{W}{\Delta t}
$$

Equação 2. Equação da potência de um trabalho

Teremos a Equação 3, que é a potência associada a uma turbina eólica:

$$
\mathrm{P}=\frac{m v^{2}}{2 \Delta t}
$$

Equação 3. Potência das massas de ar sobre as hélices de um aerogerador

Os ventos são causados por diferenças de pressão entre duas regiões ao longo da superfície terrestre. Essa diferença de pressão se dá pela como é distribuída a de radiação solar ao longo do globo terrestre. Regiões que recebem as maiores radiações apresentam o ar mais rarefeito, portanto terão uma menor pressão atmosférica. Em consequência disso, as massas de ar movimentam-se nessa direção, a fim de compensar as diferenças em termos de pressão. Regiões tropicais recebem mais radiações que outras, por isso apresentam maior incidência de ventos durante todo o ano (JACINTO, 2016).

As primeiras utilizações da energia dos ventos foram em embarcações: Fenícios,
Gregos, Romanos e Portugueses utilizavam as forças dos ventos para movimentar embarcações (PORTAL ENERGIA, 2015). Já na idade média passou-se a utilizar as forças dos ventos para a movimentação de moinhos. Os moinhos eram utilizados para a elevação de água, e também na moagem de grãos.

A energia eólica é tida por muitos pesquisadores e governos, como uma fonte alternativa de energia promissora, baseada em metodologia madura na Europa e nos Estados Unidos. Jacinto (2016) esclarece que pequenos grupos de quatro ou cinco turbinas são cada vez mais frequentes nesses lugares, e também no Brasil.

\section{O desenvolvimento da energia eólica no Brasil}

A energia eólica no Brasil teve início no começo da década de 1990 na Ilha de Fernando de Noronha no Estado de Pernambuco. Nessa época foi instalada na ilha uma turbina geradora de eletricidade a partir dos ventos de $225 \mathrm{~kW}$, parceria entre o Centro Brasileiro de Energia Eólica (CBEE) e a Companhia Energética de Pernambuco (CELPE) (ABEEÓLICA, 2017).

Apesar de ainda baixa a contribuição da energia eólica na matriz elétrica nacional, o setor tem experimentado nos últimos anos, um grande aumento no número de projetos de usinas eólicas contratas. A capacidade instalada no Brasil também teve significativo aumento e a indústria de aerogeradores vem aumentando sua capacidade de produção (SIMAS \& PACCA, 2013). Simas \& Pacca (2013) observa que o grande número de empresas de fabricação de aerogeradores surgidas na última década é uma demonstração do quanto esse é mercado é atrativo.

$\mathrm{O}$ avanço significativo da energia eólica no Brasil deu-se com a criação do PROINFA, responsável por financiar os empreendimentos eólicos no país (ABEEÓLICA, 2017). 
Até 2016 existiam 322 usinas eólicas no Brasil. Juntas, a capacidade de produção delas era de $8,12 \mathrm{GW}$, equivalente à usina hidrelétrica de Tucuruí, no Estado do Pará. O que corresponderia a $5,8 \%$ da matriz elétrica nacional. O Brasil ocupa hoje a $10^{\mathrm{a}}$ maior capacidade de produção de energia eólica no mundo, e em 2014 foi o quarto país que mais ampliou a sua capacidade produtiva (BARIFOUSE \& SCHREIBER, 2015).

O Nordeste brasileiro contribui com $75 \%$ da capacidade instalada nacional de energia eólica. Rio Grande do Norte e Ceará juntos contribuem com $55 \%$ (COSTA \& BRAGA JR., 2016). O estado do Rio Grande do Norte é o primeiro estado com mais usinas eólicas (68 no total), sendo seguido por, Bahia, Rio Grande do Sul e Ceará (CABRAL, 2017).

O Estado do Ceará, pioneiro na energia eólica, em 2016 cresceu 29\% em comparação a 2015. No mesmo período a capacidade instalada no Estado aumentou 22,6\%. No ano de 2016 a produção em MW no estado foi de 668, enquanto em 2015 a produtividade foi de 518 MW. Já a capacidade instalada passou de $1.574 \mathrm{MW}$ para 1.930 MW no mesmo período (CABRAL, 2017).

\section{Resultados e discussões}

Os vultuosos investimentos feitos na geração de energia eólica nos últimos anos têm consolidado esta, como uma das mais promissoras fontes de energia alternativa no mundo. Esta modalidade energética é a principal responsável pelo crescimento das fontes renováveis. De acordo com o International Energy Agency (IEA) (2015) a energia eólica responde por $34 \%$ da geração de energia renovável no mundo, seguido das hidroelétricas $(30 \%)$ e das heliotérmicas (18\%). O desenvolvimento acentuado dessa promissora modalidade energética desperta um interesse particular, não só para discussões acerca do ponto de vista energético sustentável, mas também da própria sustentabilidade da energia eólica quanto aos impactos socioambientais envolvidos (NETO \& LIMA, 2016).

Sustentabilidade pode ser entendida como a capacidade de se sustentar, ou seja, de se manter. Dessa forma, de uma maneira mais geral, pode-se entender a sustentabilidade como uma atividade que pode se manter para sempre. Em uma atividade sustentável o que é extraído, apresenta tempo hábil para sua recuperação e reposição. Para (MIKHAILOVA, 2004) uma sociedade sustentável é aquela que não coloca em risco os elementos do meio ambiente. Ainda de acordo com o autor o desenvolvimento sustentável é aquele que procura melhorar a qualidade de vida do homem, ao mesmo tempo em que respeita a capacidade de produção dos ecossistemas em que vivemos.

A base para a produção de energia eólica de forma aproveitável para sua distribuição, e consumo final, é a construção de parques eólicos. Estes parques eólicos, também chamados de usinas eólicas são espaços terrestres (geralmente, até pelo custo envolvido) ou marítimos, onde estão concentrados os aerogeradores, que transformam a energia dos ventos em energia elétrica (PUC-RS, 2017).

Silva \& Vieira (2016) apontam que qualquer intervenção humana na natureza gera um impacto, por mais mínimo que seja. Os autores mencionam que no caso dos parques eólicos há problemas bem inerentes e específicos. Silva \& Vieira (2016) citam casos bem específicos, como o impacto em rotas de pássaros, os efeitos nocivos aos animais causados pela frequência sonora gerada pelo movimento das turbinas, os efeitos deletérios gerados nos morcegos como a morte destes por hemorragia interna causada pelas diferenças de pressão nas regiões próximas às pás.

Apesar de comprovados benefícios tragos à economia de um país, como a menor 
dependência de combustíveis fósseis, sobretudo petróleo, que resulta em menor emissão de $\mathrm{CO}_{2}$, a instalação de parques eólicos também pode impactar negativamente regiões onde são implantados. No Quadro 1, Lopes (2012) enumera alguns danos causados às espécies da fauna local, além dos já citados:

Quadro 1. Impactos causados à fauna onde se localizam os parques eólicos

\section{Alguns impactos causados à espécies da fauna onde se localizam os parques eólicos}

\begin{tabular}{ll}
\hline 01 & Perda de habitat natural de espécies animais \\
02 & Perturbação da migração natural para espécies de aves \\
$\mathbf{0 3}$ & Alteração no sucesso reprodutor de espécies \\
$\mathbf{0 4}$ & Colisão de aves com os aerogeradores \\
\hline
\end{tabular}

Fonte: (LOPES, 2012).

Silva \& Vieira (2016) apontam que por se tratar de tecnologia recente, esses efeitos adversos que são advindos da energia eólica são mínimos, e ainda objetos de estudos e aperfeiçoamentos. Oliveira Neto \& Lima (2016) enunciam que, ao contrário dos parques eólicos, o surgimento, e a expansão de grandes hidrelétricas no Brasil, foram criados para suportar o processo de industrialização nacional surgida após a crise de 1929, e por esse motivo houve pouco planejamento a respeito na construção das mesmas, e Estudos de Impacto Ambiental (EIA).

Os critérios adotados na construção das hidrelétricas eram menos exigentes, e quando havia a necessidade de se deslocar grande contingente populacional de suas terras, ou mesmo inundar áreas inteiras, isso era feito. A esse respeito, Simas \& Pacca (2013) observam que, ao contrário das hidrelétricas, os projetos que objetivam a implementação de energias renováveis, não demandam tanto espaço territorial, e podem muito bem serem implantados em áreas rurais, onde há baixa densidade populacional.

Ainda segundo os autores os empreendimentos que exploram fontes renováveis de energia, são menores e mais dispersas que as usinas tradicionais (hidroelétricas, termoelétricas), e que, além disso, em regiões caracterizadas pelo baixo investimento econômico dos governos locais, podem ser beneficiadas. Segundo Nguyen (2007) essa característica prima pelo desenvolvimento dessas áreas, pois demanda grande quantidade de mão-de-obra para a construção das usinas, e gera empregos em potencial.

Sobre esse aspecto, Oliveira Neto \& Lima (2016) apontam que o aproveitamento de novas atividades em regiões com pouco desenvolvimento, como a Região Nordeste, é fundamental para se criar situações de econômicas favoráveis. Para os autores o fato de o Nordeste concentrar o maior potencial eólico no país possibilita o desenvolvimento da região, por meio da criação de um polo industrial dessa modalidade energética.

Apesar de serem citadas diversas vantagens a respeito da energia eólica, inclusive sob seu baixo potencial agressivo, muitos autores discordam desses apontamentos. Brow (2011) enumera na Quadro 2, alguns aspectos negativos de caráter socioambiental advindos da implementação das usinas eólicas: 
Quadro 2. Aspectos socioambientais advindos da instalação de parques eólicos.

\begin{tabular}{ll}
\hline \multicolumn{1}{c}{ Aspectos de caráter socioambientais advindos dos parques eólicos } \\
\hline $\mathbf{0 1}$ & Privatização de áreas de acesso comum \\
$\mathbf{0 2}$ & Impermeabilização do solo \\
$\mathbf{0 3}$ & Comprometimento do lençol freático \\
$\mathbf{0 4}$ & Ruídos constantes dos aerogeradores \\
$\mathbf{0 5}$ & Impedimento de áreas de lazer \\
\hline
\end{tabular}

Fonte: (BROW, 2011).

Leite \& Souza (2015) por sua vez, e ao contrário de Simas \& Pacas (2013), apontam paralelos entre o que está ocorrendo atualmente no caso dos empreendimentos eólicos, e o que houve na implantação das grandes hidrelétricas:

\begin{abstract}
No Brasil, o desenvolvimento da política energética esteve vinculado a práticas de inundação, e expulsão de populações para a formação de reservatórios e construção de hidrelétricas. Assim, ao longo da história brasileira, grandes projetos hidrelétricos foram sendo empreendidos por decisões tecnocratas. Tomadas em gabinete, em parceria com os segmentos interessados nas "benesses" econômicas a serem geradas, sem que houvesse preocupação com os diretamente atingidos - a população do local do empreendimento (LEITE \& SOUZA, 2015, p. 247)
\end{abstract}

Mendes et. al. (2016) em estudo dirigido a uma comunidade próxima de um local onde foi instalado um parque eólico constatou, dentre muitos conflitos entre o empreendimento e a comunidade, um que se sobressaiu: a inexistência de energia elétrica na comunidade. Segundo os autores, somente um ano após o funcionamento do parque eólico na comunidade, é que os moradores passaram a ter energia elétrica em suas casas. Ainda segundo os autores, o fato de estarem tão próximos a uma usina geradora de eletricidade, e não disporem desse bem, causou mal-estar entre a população, que impulsionou reinvindicações do poder público e também dos donos do empreendimento.

O fornecimento de energia elétrica é responsabilidade do poder público, mas o autor comenta que os donos do empreendimento, pelo relato de moradores, dificultaram o acesso à energia elétrica pela população.

De acordo com a Pastoral da Terra da Bahia os empreendimentos eólicos atingem diretamente os povos quilombolas. Segundo os levantamentos da entidade as empresas estão adquirindo terras de uso coletivo, e realizando contrato de arrendamentos que não resguardam os direitos fundamentais dos moradores (PORTO \& FERREIRA, 2013).

Além desses aspectos que questionam o aspecto inclusivo da energia eólica, há também os problemas de ordem socioambientais:

1. As turbinas eólicas geram impacto visual difícil de mensurar. Os corpos das turbinas apresentam altura próxima de 40 metros, enquanto suas hélices apresentam comprimento entorno de $20 \mathrm{~m}$. Pelas dimensões são notáveis as transformações que a paisagem de uma localidade passa (INATOMI \& UDAETA, 2005).

2. Santos \& Souza (2016) observam que a evolução nas atividades do segmento eólico vem causando alterações principalmente nos solos, que respondem pela base de toda a existência do setor eólico.

3. Um aspecto levantado por Inatomi \& Udaeta (2005) é a circulação padrão do ar. Após a operacionalização das turbinas, o ar é modificado, o que afeta o clima local, chegando a formar microclimas.

4. O impacto sonoro está entre as principais desvantagens da produção de energia eólica. Quando as massas de ar atingem as pás dos 
aerogeradores provoca um constante, de aproximadamente $43 \mathrm{~dB}$. Para que a população não seja atingida as habitações mais próximas deverão estar a $200 \mathrm{~m}$ das usinas (PORTAL ENERGIA, 2015).

O ruído produzido por turbinas aerogeradoras está diretamente associado às caixas de velocidades, ao gerador elétrico, e a motores auxiliares. Estes três equipamentos estão diretamente relacionados às pás (hélices) dos aerogeradores, portanto, esse ruído torna-se inevitável, principalmente quando há baixa velocidade dos ventos. Ainda mais, quando há velocidades maiores dos ventos, o ruído de fundo se sobrepõe ao das turbinas (Jacinto, 2016).

Já Cardoso \& Collischonn (2015) em pesquisa feita com moradores próximos a um parque eólico, no Estado do Rio Grande do Sul, obteve resultados expressivamente favoráveis à Usina Eólica em muitos aspectos. Do grupo de pessoas entrevistadas pelo autor, $85 \%$ afirmaram ter afinidade pelo empreendimento, e todos (100\%) disseram ter uma visão agradável do parque na vizinhança. $65 \%$ desses entrevistados ainda afirmaram que o parque trouxe progresso e destaque para a cidade.

Considerações a respeito da instalação de usinas eólicas

Jacinto (2016) ressalta que os projetos destinados à energia eólica devem ser adequadamente inseridos na paisagem e no desenvolvimento local, afim de que haja uma minimização dos impactos. Já Porto et. al. (2013) observam que as tecnologias denominadas "limpas" e sustentáveis, por meio de uma visão restrita de ecoeficiência ou economia verde podem gerar conflitos e injustiças ambientais, principalmente no atual contexto energético.

A Lei $\mathrm{n}^{\circ} 12.651$ de 25 de maio de 2012 estabelece a obrigação de manutenção da vegetação em Áreas de Proteção
Permanente (APP), entretanto, esta mesma lei prevê exceções a essa manutenção. Quando as modificações forem para benefícios públicos, de interesse social ou de baixo impacto ambiental, a Lei permite que haja modificações em APP. Dessa forma, o próprio código florestal permite que haja instalação de parques eólicos em áreas protegidas, em razão do enquadramento como obra de utilidade pública (Costa e Bragra Jr., 2016).

Segundo levantamento feito pelo Jornal Diário do Nordeste, todas as usinas eólicas implantadas no Estado do Ceará entre 2007 e 2010 foram em APPs. O jornal informa que as obras embora licenciadas, não passaram por um completo Estudo de Impacto Ambiental (EIA). De acordo com Viana et. al. (2016) as dimensões dos impactos sobre as comunidades atingidas tendem a ser minorizadas, ou até mesmo invisíveis nos processos de licenciamento ambiental, pincipalmente por meio do subdimensionamento das implicações socioambientais do empreendimento.

Diversos estudos e pareceres ambientais para o licenciamento desses empreendimentos, contratados pelas próprias empresas, revelam omissão dos impactos sobre comunidades tradicionais diretamente afetadas pelos parques eólicos. O que se adota nesses documentos é a concepção de que as áreas apresentam baixa densidade demográfica, e praticamente despovoada (Viana et. al., 2016).

Leite \& Souza (2015) observam a necessidade de que haja a participação efetiva de grupos sociais, diretamente atingidos por empreendimentos energéticos, nos processos decisórios, principalmente os que envolvem os ascendentes empreendimentos eólicos, que se multiplicam ao longo dos litorais dos estados Nordestinos. O autor ainda enfatiza que apenas com a participação da sociedade local, juntamente com metodologias adequadas, que envolvam preceitos da equidade ambiental, será garantida a realização de justiça ambiental. 


\section{Considerações finais}

Observa-se que as atividades relacionadas às energias renováveis estão se configurando como um caminho sem volta, e é exatamente sob este aspecto que essas novas fontes de energia devem ser questionadas, já que a tendência é de se consolidarem, quais perspectivas em relação aos seus potenciais sustentáveis.

$\mathrm{O}$ que se tem levado muito em conta hoje é o fato da inclusão de fontes energéticas renováveis na matriz elétrica nacional, ser uma forma de mitigar impactos ambientais provocados pela obtenção tradicional de energia elétrica. Entretanto foi possível observar no presente trabalho, que mesmo as fontes renováveis, apresentam pontos negativos sob esse aspecto, e estes não devem ser ignorados. $O$ que é discutido até o momento, principalmente em veículos de comunicação de massa, é o lado vantajoso dessas modalidades energéticas, principalmente quando se trata da energia eólica. Entretanto é necessário que ambos os aspectos sejam discutidos e evidenciados, e que se possa conhecê-los e quantificá-los para um melhor esclarecimento e planejamento, tendo como um dos focos principais o lado social e ambiental.

Pelo exposto no trabalho, vê-se que até a mais consensual das alternativas energéticas é capaz de gerar inúmeros conflitos ambientais. No que concerne à energia eólica, entende-se que o reconhecimento dos conflitos socioambientais existentes hoje, da forma como estão sendo geridos, põe em cheque $o$ discurso de sustentabilidade praticado por esse meio de energia.

Além dos conflitos socioambientais, um problema associado à geração da energia eólica é exatamente sua forte dependência dos ventos. Por isso, mesmo em regiões como o Nordeste, destaque em termos de ventos fortes, o fornecimento de energia eólica pode vim a tornar-se intermitente.
O presente trabalho buscou por meio de artigos já publicados, dá uma ênfase aos conflitos inerentes e específicos à implantação de usinas eólicas para a geração de energia elétrica, exaltando principalmente os parques instalados em zonas costeiras, onde a população nativa apresenta maior vinculo com a terra e com as atividades pesqueiras, e também onde está localizada a maioria dos parques eólicos. Apesar de ser uma modalidade em processo de expansão recente, os conflitos advindos já são bastante consideráveis. Espera-se com esse trabalho contribuir para posteriores pesquisas sobre o assunto, e embasar discussões futuras.

\section{Referências bibliográficas}

\section{ABEEÓLICA. Energia eólica - o setor. Disponível em:< http://www.abeeolica.org.br/energia-eolica-o- setor/>. Acesso em: 29 de abril de 2017.}

ABREU, M. C. S.; SIEBRA, A. A.; CUNHA, L. T. da; SANTOS, S. M. dos. Fatores determinantes para o avanço da energia eólica no Estado do Ceará frente aos desafios das mudanças climáticas. Revista Eletrônica de Administração, Porto Alegre (RS), edição 78, n. 2, p. 274 - 304, mai./ago. 2014.

BARIFOUSE, R.; SCHREIBER, M. Como o Nordeste virou principal polo da energia eólica no Brasil. BBC Brasil, Brasília/São Paulo, 13 de nov. 2015. Disponível em:< http://www.bbc.com/portuguese/noticias/2015 /11/151110_energia_eolica_nordeste_rb >. Acesso em: 30 de abril de 2017.

BROWN, K. B. Wind power in northeastern Brazil: local burdens, regional benefits and growing opposition. Climate and Development, v. 3, p. 344 - 360, 2011.

CABRAL, B. Geração de energia eólica no Ceará salta 29\%. Diário do Nordeste (Caderno Negócios), Fortaleza - Ceará, 14 de fev. de 2017. Disponível em:< http://diariodonordeste.verdesmares.com.br/ca 
dernos/negocios/geracao-de-energia-eolicano-ce-salta-29-1.1704392>. Acesso em 25 de abril de 2017.

CARDOSO, A. M.; COLLISCHONN, E. Parques de produção de Energia eólica e transformações na paisagem: estudo de caso em Santa Vitória do Palmar (RS). Boletim Geográfico do Rio Grande do Sul, Porto Alegre, n. 25, p. 82 - 97, ago. 2015.

CARDOSO, J. M. de M. Equações matemáticas e conceitos físicos aplicados a uma turbina eólica vertical de pequeno porte. Revista Brasileira de Iniciação Científica. Itapetininga, v. 2, n. 3, 2015.

COSTA, V. H. G.; BRAGA JÚNIOR, S. A. de M. Aspectos da discricionariedade e da proporcionalidade no licenciamento ambiental e a análise de projetos eólicos em áreas de preservação permanente. Revista do Mestrado em Direito, Brasília (DF), v. 10, n. 1, p. $86-128$, jan./jun. 2016.

GOLDEMBERG, J.; LUCON, O. Energia e meio ambiente no Brasil. Estudos avançados, v. 21, n. 59, p. 7 - 20, 2007.

INATOMI, T. A. H.; UADETA, M. E. M. Análise dos impactos ambientais na produção de energia dentro do integrado de recursos. In: WORKSHOP INTERNACIONAL BRASILJAPÃO, 3., 2005, Campinas (SP). Anais. Campinas, 2005.

JACINTO, E. de A. S. Determinação do potencial eólico do município de Barreirinhas/MA. 2016, 27 p. Monografia (Graduação de Bacharel em Agronomia) Centro de Ciências Agrárias e Ambientais, Universidade Federal do Maranhão, Chapadinha (MA). 2016.

LEITE, D. B.; SOUZA, E. P. de. Tendências do cenário energético brasileiro: a energia de fonte eólica e o olhar dos atingidos. Revista Ciência e Natura, Santa Maria (RS), v. 37, n. 4, p. 243 - 250, set./dez. 2015.

LOPES, R. A. Energia Eólica. $2^{a}$ Ed. São Paulo: Liber, 2012.
MARTINS, F. R.; GUARNIERI, R. A.; PEREIRA, E. B. O aproveitamento da energia eólica. Revista Brasileira de Ensino de Física, v. 30, n. 1, 2008.

MARTINS, E. F.; LIMA, G, B. A.; GOMES, H. C. Análise estratégica multicritério sócioeconômico-ambiental como ferramenta de apoio à decisão em uma empresa de distribuição de energia. Revista Eletrônica Sistemas \& Gestão, Niterói (RJ) Universidade Federal Fluminense (Departamento de Engenharia de Produção), v. 10, n. 1, p. 96 - 106, 2015.

MENDES, J. de S.; GORAYEB, A.; BRANNSTROM, C. Diagnóstico participativo e cartografia social aplicados aos estudos de impactos das usinas eólicas no litoral do Ceará: o caso da Praia de Xavier, Camocim. Geosaberes, Fortaleza (CE), Universidade Federal do Ceará, v. 6, número especial (3), p. 243 - 254, fev. 2016.

MIKHAILOVA, I. Sustentabilidade: evolução dos conceitos teóricos e os problemas da mensuração prática. Revista Economia e Desenvolvimento, n. 16, 2014.

MINAYO, M. C. de S. O desafio do conhecimento: pesquisa qualitativa em saúde. São Paulo: Hucitec- Abrasco, 1994.

MOREIRA, R. N.; VIANA, A. F.; OLIVEIRA, D. A. B. de; VIDAL, F. A. B. Energia eólica no quintal da nossa casa?! Percepção ambiental dos impactos socioambientais na instalação e operação de uma usina na comunidade de Sítio de Cumbe em Aracati - CE. Revista de Gestão Ambiental e Sustentabilidade, São Paulo (SP), v. 2, n. 1, p. 45 - 73, jan/jun. 2013.

NGUYEN, K. Q. Alternatives to grid extension for rural electrification: descentralized renewable energy technologies in Vietnam. Energy Policy, v. 35, n. 4, p. 2579 - 2589, abr. 2007.

OLIVEIRA NETO, C. R. de; LIMA, E. C. de. Mercado eólico e desenvolvimento regional: perspectiva de formação de uma indústria eólica motriz para o Nordeste Brasileiro. 
Revista Orbis Latina, Foz do Iguaçu (PR), v. 6, n. 2, p. 129 - 153, jul/dez, 2016.

PORTAL ENERGIA. Vantagens e desvantagens da energia eólica. 2015. Disponível em: <https://www.portalenergia.com/vantagens-desvantagens-daenergia-eolica/ $>$. Acesso em: 01 de maio de 2017.

PORTO, M. F. de; FINAMORE, R.; FERREIRA, H. Injustiças da sustentabilidade: conflitos ambientais relacionados à produção de energia "limpa" no Brasil. Revista Crítica (Ciências Sociais), n. 100, p. 37 - 64, maio. 2013.

PUC - RS - Pontifícia Universidade Católica do Rio Grande do Sul. CE - Eólica (Centro de Energia Eólica). Disponível em:< www.pucrs.br/ce-eolica/faq.php?q=27\#27>.

Acesso em 30 de dezembro de 2017.

RODRIGUES, M. A. C. Diagnóstico de avarias em sistemas de conversão de energia eólica. 2017, 100 p. Dissertação (Mestrado Integrado em Engenharia Eletrotécnica de Computadores), Faculdade de Engenharia, Universidade do Porto, Porto. 2017.

SANTOS, W. A. A. dos; SOUZA, H. C. de. Atuação, monitoramento e análise de processos erosivos no âmbito de parques eólicos: estudo de caso nas regiões litorânea e agreste do Nordeste Brasileiro. REGINE, v. 2, n. especial, p. 133 - 142, 2016.

SILVA, A. M.; VIEIRA, R. M. F. Energia eólica: conceitos e características basilares para uma possível suplementação da matriz energética brasileira. Revista Direito Ambiental e Sociedade, v. 6, n. 2, p. 53 - 76, 2016.

SIMAS, M.; PACCA, S. Energia eólica, geração de emprego e desenvolvimento sustentável. Estudos Avançados, v. 27, n. 77, 2013.

VIANA, L. A.; NASCIMENTO, J. L. J. do; MEIRELES, A. J. de A. Complexos eólicos e injustiças ambientais: mapeamento participativo e visibilização dos conflitos provocados pela implantação de parques eólicos no Ceará. Revista do Programa de Pós-graduação em Geografia (UFPR), v. 11, n. 1, p. $64-83$, jul. 2016. 